\title{
The role of experiential value, novelty, and satisfaction in robot barista coffee shop in South Korea: COVID-19 crisis and beyond
}

\author{
Seon Hee $\mathrm{Kim}^{1} \cdot$ Se Ran $\mathrm{Yoo}^{2} \cdot$ Hyeon Mo Jeon ${ }^{3}$ (D
}

Received: 19 July 2021 / Accepted: 21 October 2021 / Published online: 31 October 2021

(C) The Author(s), under exclusive licence to Springer-Verlag GmbH Germany, part of Springer Nature 2021

\begin{abstract}
The purpose of this study is to examine the effects of experiential value and novelty on the formation of customer satisfaction and behavioral intention towards a robot barista coffee shop (RBCS). For the analysis, a set of hypotheses was developed and tested based on data collected from 300 customers who had visited a RBCS in South Korea. The findings of the study confirmed the importance of atmosphere, novelty, and consumer return on investment as factors that influence satisfaction and behavior intention. This study contributes to the existing knowledge about experiential value by suggesting important factors that can predict consumer behavior towards RBCS and practical insights for coffee shop management according to untact consumption changes were proposed.
\end{abstract}

Keywords Robot barista $\cdot$ Experiential value $\cdot$ Novelty $\cdot$ Satisfaction $\cdot$ Behavioral intention $\cdot$ Coffee shop $\cdot$ South Korea

\section{Introduction}

In the era of the 4th industrial revolution, hospitality companies are increasingly using artificial intelligence (AI) technology and automated equipment systems, including robots (Lin et al. 2020). The development of information and communication technology (ICT) brought a new trend of food tech in food and beverage stores (Tuomi et al. 2021). Food tech (food + technology) refers to a new industry that combines the food industry with ICT. After the declaration of the COVID-19

Hyeon Mo Jeon

jhm010@dongguk.ac.kr

1 Department of Tourism Management, Gachon University, Seongnam, Republic of Korea

2 Graduate School, Kyung Hee University, Seoul, Republic of Korea

3 Department of Hotel, Tourism, and Foodservice Management, Dongguk University-Gyeongju, Gyeongju 38066, Republic of Korea 
pandemic in March 2020 (World Health Organization 2020), consumers turned their offline daily life into online digital consumption that secures social distance (Ali et al. 2021). As consumers in the post-COVID-19 era also choose to focus on the safety and reliability of products and services according to environmental changes, the change in food tech has accelerated commercialization in response to the pandemic (Zeng et al. 2020).

In the foodservice industry, robots are being used in various sectors as 'food tech' is accelerated. Although some of these robots perform basic and routine tasks (e.g., robotic floor cleaners) in hotels and restaurants (Murphy et al. 2017), a growing number of them are performing more advanced frontline tasks (e.g., talking, serving food) that involve engaging customers at the social level (Belanche et al. 2020). From delivery robots, serving robots, and chef robots to chicken robots, pizza robots, coffee robots, and ice cream robots, technology-oriented services have become popular (Jang and Lee 2020). Robots are emerging from industrial robots to become a representative service means in the (no contact) untact era (Lee and Lee 2020). With this trend, the enthusiasm for food tech is spreading in the coffee shop business and robot barista services are on the rise (Sung and Jeon 2020). In South Korea, the robot café "Beat" of coffee brand Dalcomm Coffee has updated the latest model "Bit $2 \mathrm{E}$ " robot equipped with artificial intelligence by introducing $5 \mathrm{G}$ network technology (Infostock Daily 2020). Folletto has developed a coffee robot machine, "Happy Bones", capable of various latte art and is about to be released (Robot newspaper 2020).

It is expected that the robot barista service of coffee shops will be further expanded as the speed of introduction of automation technology by foodservice companies is accelerated due to the preference for untact services and the convergence of innovative technologies after Covid-19 (Lin et al. 2020). Despite this situation, empirical research on robot service experience in the food service industry has not been widely conducted. Therefore, this study examines the influence of a robot barista customer's perceived experience value on customer satisfaction and behavioral intention by incorporating robot service, a representative untact service method, into the coffee shop market. Experiential value refers to customers' perceived relative preference for product attributes or service performance provided by service contact points as a cognitive evaluation of the value that customers directly experience in the service context (Mathwick et al. 2001). This experiential value is an important factor that positively affects customer satisfaction because it can measure enjoyment and various emotional values (Chiang 2018; Hung et al. 2019).

The experiential value in the hospitality industry has been mainly applied to studies on the use of general human service stores (Kim and Stepchenkova 2018; Jin et al. 2013; Taylor et al. 2018). This study, different from previous studies, applies it to robot barista stores, a kind of untact service. This is the biggest difference from previous studies that applied experience value. Additionally, this study applies novelty as a factor that increases customer satisfaction with information and communication technology. Novelty value refers to the innovation that a company provides to its customers. Without innovation in the customer's experience environment, the customer is not satisfied (Pham and Huang 2015). Novelty is originality perceived in the comparison between present awareness and prior experiences and comprises 
four dimensions: thrill, adventure, surprise, and soothing boredom (Lee and Crompton 1992). The experience of novelty affects positive emotions and satisfaction (Kim 2010; Lee et al. 2017) and word of mouth (Dedeoglu et al. 2018). Recently, novelty has been applied as an important variable in research on accepting the 4th industrial revolution technology (Jheng et al. 2020; Karjaluoto et al. 2019). Therefore, a clear understanding of the consumer's novelty and the robot barista service is required to satisfy the needs of digital consumers who seek new experiences. Satisfaction with untact services in the hospitality industry has led consumers to repeatedly purchase products or services (Adekunle and Ejechi 2018; Alalwan 2020), and satisfied customers positively affect recommendation intentions (Sharma and Kumar 2019). Therefore, understanding the predictors that affect customer satisfaction can help the sustainable management of RBCSs.

The purpose of this study is to examine the influential relationship between variables by applying the experience value, novelty, satisfaction, and behavioral intention to the consumer behavior study of the RBCS customers providing untact service. This research design is differentiated from previous studies on experiential value that have been focused on human services in the hospitality industry (Hung et al. 2019; Jin et al. 2013; Taylor et al. 2018) on experiential value. The analysis' results can potentially suggest important factors that can predict consumer behavior towards RBCS in the future, which will contribute to the hospitality literature. Practical implications for establishing efficient marketing strategies for RBCSs are presented based on the research results. Additionally, it provides basic data for research for the stable acceptance and expansion of the 4th industrial revolution technology in the future food and beverage business. The rest of this paper is structured as follows. Section 2 presents the literature review and proposes the hypotheses. Section 3 introduces the methodology. Section 4 presents the data analysis and results. Section 5 presents the theoretical and practical implications. In the final section, limitations are drawn and recommendations are proposed.

\section{Literature review and hypotheses}

\subsection{Experiential value and satisfaction}

The overall consumption experience is an important aspect of consumer value perception, especially in the service industry (Keng et al. 2007; Mathwick et al. 2001; Taylor et al. 2018). Holbrook (1994) argued through existing traditional value studies that consumers prefer specific experiences or objects when they achieve a purpose or profit in purchasing products and services, derived from interactions between products and customers (Wu and Liang 2009). Additionally, previous studies have shown that creating value by enhancing the consumer experience implies an effort to improve the quality of relationships (Taylor et al. 2018; Wu and Liang 2009). Therefore, the concept of experiential value refers to the customer's perception of the value from the consumption experience (Jin et al. 2013; Kim and Stepchenkova 2018). 
Holbrook (1994), a representative researcher of experiential value, presented it as three spheres: extrinsic and intrinsic, active and reactive, and self-oriented and other-oriented (Yuan and Wu 2008). In general, personal experiences such as shopping are regarded as self-oriented activities. Thus, experiential values are classified into extrinsic or intrinsic and active or reactive (Kim and Stepchenkova 2018). Combining the two dimensions labeled by Mathwick et al. (2001) and Jin et al. (2013), four aspects of experiential value are derived: consumer return on investment (active sources of extrinsic value), service excellence (reactive sources of extrinsic value), atmosphere or aesthetics (reactive sources of intrinsic value), and escapism (active sources of intrinsic value) (Chiang 2018; Kim and Stepchenkova 2018; Tsai and Wang 2017). Additionally, it can be seen that the perception of experiential value is based on interactions related to direct usage or distant evaluations of goods or services based on consumer preferences (Mathwick et al. 2001).

These dimensions of experiential value, consumer return on investment (CROI), service excellence, atmosphere and aesthetics, and escapism, are essential for building and maintaining positive relationships (satisfaction) with customers, leading to high levels of loyalty (Jin et al. 2013; Keng et al. 2007; Mathwick et al. 2001; Wu and Liang 2009). First, CROI is the return on financial, temporal, behavioral, and psychological resources actively invested by consumers during consumption (Mathwick et al. 2001; Tsai and Wang 2017). It can be called economic utility, affordability, and the utility of a consumption encounter in general (Mathwick et al. 2001). Consumers can experience these returns in terms of economic utility value. Consumers are satisfied when they feel they receive greater economic value than those who offer the same product (Chiang 2018).

Second, service excellence is a subjective, extrinsic, and reactive value (Mathwick et al. 2001) and is evaluated as the extent to which the service or product meets customer expectations (Keng et al. 2007). Accordingly, the value of service excellence can be said to be a consumer's judgment (satisfaction) of service providers who demonstrate professionalism and maintain reliable services (Oliver and DeSarbo 1988).

Third, atmosphere or aesthetics is further dimensionalized, focusing on entertainment and visual appeal (Kim and Stepchenkova 2018; Mathwick et al. 2002) as a response to the correspondence, performance, and harmony of physical objects (Maghnati and Ling 2013). This recognition of good atmosphere and aesthetics generates feelings of pleasantness, service satisfaction, and the intention to reuse that service (Vilnai-Yavetz and Rafaeli 2006). Therefore, atmosphere or aesthetics can be a factor that reduces the difference between expectations and performance and improves both customer satisfaction and loyalty (Ryu and Han 2011; Tsai and Wang 2017).

Fourth, escapism is defined as intrinsic enjoyment that comes from engaging in absorbing activities to the point of offering an escape from the demand of the dayto-day world (Mathwick et al. 2001). Escapism brings potential pleasure and emotional value through deviation from daily life and can act as an important factor that ultimately attracts customers (Yuan and Wu 2008). Enhancing the perceived values of these traits can stimulate the senses and emotions, thus solidifying the sense of satisfaction and willingness to act (Ryu et al. 2010). 
Consumers have their expectations and or past experiences before they experience products and services, which influence the process of experiencing products and services and their subsequent satisfaction (Berry et al. 2002; Pham and Huang 2015). Thus, the positive experiential value perceived by consumers is a direct variable that improves satisfaction (Gallarza and Saura 2006; Yuan and Wu 2008), and the four spheres of experiential value can be regarded to be important predictors that promote consumer satisfaction. Several previous studies have identified a significant relationship between experiential value (especially divided into four spheres) and satisfaction (Chiang 2018).

Chiang (2018) found that CROI has the greatest influence among the factors of experiential value on satisfaction with online to offline $(\mathrm{O} 2 \mathrm{O})$ goods. Jin et al. (2013) reported that full-service restaurant customers are most satisfied with CROI. Taylor et al. (2018) also confirmed that CROI is a factor that increases customer satisfaction. Therefore, the following hypothesis is proposed.

HI CROI has a significant positive effect on satisfaction.

Chiang (2018) found that the service excellence of $\mathrm{O} 2 \mathrm{O}$ stores increases customer satisfaction. In the restaurant context, Jin et al. (2013) and Taylor et al. (2018) confirmed that service excellence is an antecedent that positively affects customer satisfaction. Hung et al. (2019) stated that the staff's service excellence at cultural tourism destinations increases satisfaction with cultural tourism destinations. Therefore, the following hypothesis is proposed.

$\mathrm{H} 2$ Service excellence has a significant positive effect on satisfaction.

Jin et al. (2013) stated that the aesthetics of a full-service restaurant have a positive effect on customer satisfaction. Hung et al. (2019) confirmed that the aesthetics of cultural tourism destinations increase satisfaction. Chiang (2018) confirmed that the aesthetics of $\mathrm{O} 2 \mathrm{O}$ goods are a positive antecedent for customer satisfaction. Therefore, the following hypothesis is proposed.

H3 Atmosphere has a significant positive effect on satisfaction.

Taylor et al. (2018) stated that escapism perceived in pop-up restaurants is the most important antecedent for increasing satisfaction and trust. Hung et al. (2019) reported that escapism and enjoyment increase visitor satisfaction in cultural tourism destinations. Therefore, the following hypothesis is proposed.

H4 Escapism has a significant positive effect on satisfaction.

\subsection{Novelty and satisfaction}

Novelty emerges through an internal drive that an individual activates when new information is found (Hirschman 1980). It is also a new feeling that customers feel when a service arouses curiosity and satisfies the desire for knowledge in the process of an enhancing experience (Sheth et al. 1991). Consumers who want to select a new product or service are inevitably eager to find new information, and novelty is defined as the intended behavior to acquire such new information (Hirschman 1980). 
Additionally, Lee and Crompton (1992) viewed novelty as a desire to deviate from family and neighbors, to meet new people, to discover new aspects of a person they already know, or to discover a true appearance, defining it as a change from daily life, thrill, relief from boredom, and surprise based on the motive for pursuing novelty. Therefore, novelty is a difference in perception of the prior experience and the present reality, meaning a new and unfamiliar experience different from previous experiences (Albaity and Melhem 2017).

Consumers compare certain stimuli that appeared with stimuli that they experienced in the past and acknowledged novelty when the present perception is greater than the prior experience (Lee and Crompton 1992). Therefore, pursuing novelty is related to the pursuit of diversity and is an important factor in consumers' choice motives and decision-making (Petrick 2002). It refers to the consumers' tendency to switch from their choices in the most recent situations (Ratner et al. 1999). Therefore, if the degree of novelty is perceived as low, consumers will not be sufficiently satisfied if an environment to experience novelty is not provided (Pham and Huang 2015). However, if consumers pursue newness and perceive the experience as meeting or exceeding expectations, they will be satisfied (Toyama and Yamada 2012). Additionally, it has been confirmed in several previous studies that satisfaction is a concept that positively connects novelty and loyalty (Albaity and Melhem 2017; Toyama and Yamada 2012). Major studies by Chua et al. (2015) on vacationer's cruise and by Pham and Huang (2015) on Vietnamese hotel customers in the hospitality industry confirmed a significant positive relationship between novelty and satisfaction. Furthermore, Albaity and Melhem (2017) and Toyama and Yamada (2012) targeting travelers, verified the relationship between novelty, satisfaction, and loyalty. Based on these prior studies, the following hypothesis was established and presented.

H5 Novelty has a significant positive effect on satisfaction.

\subsection{Satisfaction and behavioral intention}

Satisfaction is a very important factor in achieving loyalty and profitability (Pham and Huang 2015). Customers who experience high satisfaction contribute positively to creating new customers and increasing corporate profits through repetitive purchases and positive word of mouth. Thus, corporate management and interest in satisfaction are essential (Fornell 1992). Oliver (1997) argues that satisfaction is a value judgment that is the function of a product or service, or that the product or service itself provides fulfilment related to satisfactory consumption. Hence, satisfaction is the response of the fulfilment adopted to understand and evaluate the value through consumer experience. If a product's performance or service perceived by the consumer is higher than expected, this leads to satisfaction because the expectation is positively inconsistent. However, if the performance is lower than expected, it results in dissatisfaction because it is negatively inconsistent, affecting the behavioral intention such as revisit (repurchase) intentions and recommendation intentions. (Oliver 1980). Consequently, increasing consumer satisfaction leads to actual repurchase (use) behavior and intention (Bolton and Lemon 1999). 
There is already empirical evidence in many preceding studies that satisfaction is a strong indicator of repeated purchases and recommendations of products or services (Taylor and Baker 1994). Additionally, several prior studies have been conducted in which satisfaction with a product or service is a primary behavioral intention variable (Anderson and Mittal 2000; Zeithaml et al. 1996). In the hospitality industry, a study by Ryu and Han (2011) confirmed a significant relationship between satisfaction and behavioral intention for customers of upscale Chinese restaurants in the United States. And Qin and Prybutox (2008) identified the positive effect of satisfaction on the behavioral intention for users of fast-food restaurants. Taylor et al. (2018) found that experiential value satisfaction positively affects behavioral intention in a study on pop-up restaurants. As such, behavioral intention, an outcome variable having a positive relationship with satisfaction (Szymanski and Henard 2001), is an individual's will and belief to express certain behaviors in the future after consumers form their attitude toward an object (Boulding et al. 1993). Behavioral intention is a concept that encompasses positive behaviors such as revisiting through satisfaction and positive word of mouth effects and negative behaviors such as conversion and negative word of mouth effects due to dissatisfaction (Zeithaml et al. 1996). Based on these previous studies, the following hypothesis was established.

H6 Satisfaction has a significant positive effect on behavioral intention.

All the hypotheses are in the theoretical model, depicted in Fig. 1.

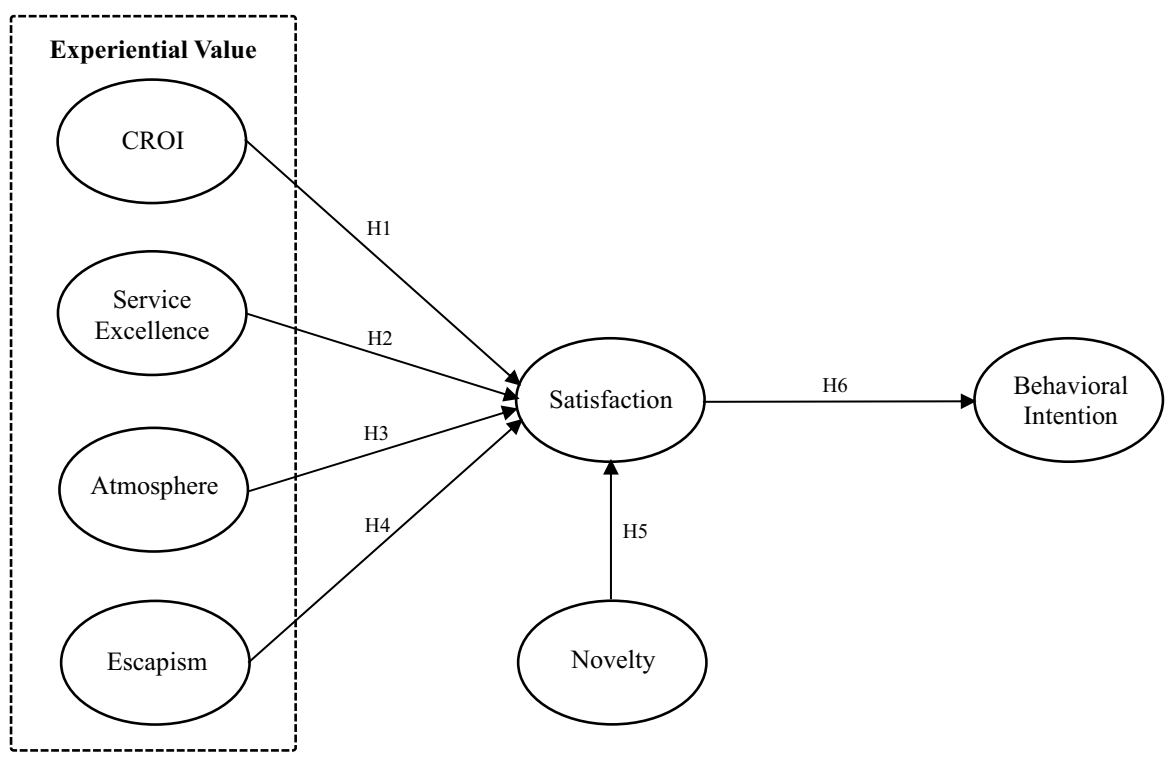

Fig. 1 Research model 


\section{Methodology}

\subsection{Sampling and data collection}

Both male and female South Korean residents over the age of 20 who have used a robot barista at a coffee shop within the last three months were selected as subjects for sampling in this study. Through the pilot test, the identified RBCS most frequently used by coffee consumers were identified for the survey-Café AI, Dalkomm B; eat, Lounge'X, and Coffee Methodx. These four coffee shop users are representative of all RBCSs.

Data was collected online from January 6 to 20, 2021, through ENTRUST. Entrust is a global online research company with offices in South Korea and Hong Kong and is a trusted professional research firm with a panel size of over 560,000 people. Screening questions were administered before the respondent was invited for an interview. Survey subjects were asked if they had any experience purchasing menus made by robot baristas by visiting coffee shops of the four brands within the last three months. After explaining the purpose of this study to the subjects who responded with experience, the investigation was conducted after prior consent. Questionnaires were presented to all respondents in the same order, and finally, 300 respondents were used for empirical analysis. Table 1 shows the profile of the sample. Since the net response rate was $10.6 \%$, this dataset was subject to non-response bias analysis using wave analysis. Responses collected within the first seven days were classified as "initial responses," and those collected during the last seven days were classified as "late responses." Independent t-tests were performed using both these groups, and the difference between them was found to be insignificant. This shows that there is no non-response bias within the dataset.

\subsection{Research instrument}

This study consisted of a total of seven factors, including perceived CROI, service excellence, atmosphere, escapism, novelty, satisfaction, and behavioral intention. The four CROI items were cited from the studies by Kim and Stepchenkova (2018), Taylor et al. (2018), and Tsai and Wang (2017), and the three questions of service excellence were cited in the studies by Rezaei and Valaei (2017), Taylor et al. (2018), and Tsai and Wang (2017). Five items of atmosphere and four items of escapism were cited in the studies by Kim and Stepchenkova (2018) and Tsai and Wang (2017), and four items of novelty were cited by Kim et al. (2012) and Manthiou et al. (2017). The four questions of satisfaction were cited in the study by Song et al. (2019) and $\mathrm{Wu}$ (2017), and the four questions of behavioral intention were cited by Sung and Jeon (2020) and Wu (2017).

The questionnaire was composed primarily through the review of previous studies, and it was modified to fit the RBCS situation. Secondly, after filling out the first questionnaire, a panel of experts composed of three professors of food service management and three RBCS operators were asked for reviews on the composition 
Table 1 Respondents' profile

\begin{tabular}{|c|c|c|}
\hline Demographic characteristics & Frequency & Percentage \\
\hline \multicolumn{3}{|l|}{ Gender } \\
\hline Male & 140 & 46.7 \\
\hline Female & 160 & 53.4 \\
\hline \multicolumn{3}{|l|}{ Age } \\
\hline $20-29$ years & 71 & 23.7 \\
\hline 30-39 years & 117 & 39.0 \\
\hline 40-49 years & 63 & 21.0 \\
\hline $50-59$ years & 31 & 10.3 \\
\hline Above 60 years & 18 & 6.0 \\
\hline \multicolumn{3}{|l|}{ Marital status } \\
\hline Single & 134 & 44.7 \\
\hline Married & 166 & 55.3 \\
\hline \multicolumn{3}{|l|}{ Educational level } \\
\hline High school & 19 & 6.3 \\
\hline 2-year university & 30 & 10.0 \\
\hline 4-year university & 223 & 74.3 \\
\hline Graduate school & 28 & 9.3 \\
\hline \multicolumn{3}{|l|}{ Annual income } \\
\hline Below USD 20,000 & 26 & 8.7 \\
\hline USD $20,000-29,000$ & 46 & 15.3 \\
\hline USD 30,000-39,000 & 57 & 19.0 \\
\hline USD $40,000-49,000$ & 48 & 16.0 \\
\hline USD 50,000-59,000 & 40 & 13.3 \\
\hline USD $60,000-69,000$ & 30 & 10.0 \\
\hline USD 70,000-79,000 & 25 & 8.3 \\
\hline Above USD 80,000 & 28 & 9.3 \\
\hline \multicolumn{3}{|l|}{ Occupation } \\
\hline Office workers & 179 & 59.7 \\
\hline Professional job & 29 & 9.7 \\
\hline Sales and service & 22 & 7.3 \\
\hline Student & 20 & 6.7 \\
\hline Technician & 17 & 5.7 \\
\hline House maker & 15 & 5.0 \\
\hline Self-employed & 14 & 4.7 \\
\hline Others & 4 & 1.3 \\
\hline
\end{tabular}

and contents of the questionnaire. Since all the questions in the questionnaire were previously developed in English, the questionnaire was re-developed using the double translation protocol (Harkness 2011). Two professors who had sufficient understanding of this study and were bilingual (Korean-English) first translated the questionnaire into Korean for the purposes of the study. Before the survey, a pilot test was conducted to check whether the survey participants could fully understand the 
questions. After the pilot test, the questions that were difficult to accurately measure were deleted through exploratory factor analysis, and the questions were corrected and supplemented with appropriate expressions to prepare the final questionnaire. After the survey was completed, the Korean version was translated into English by two bilingual professors (Korean-English) in the relevant field to allow for the thesis to be written. There was little difference between the two English versions of this questionnaire. All scales were measured on a 5-point Likert scale, from "strongly disagree to strongly agree."

\subsection{Analytical methods}

This study used SPSS 22.0 and AMOS 22.0 as analysis tools. First, the demographic characteristics of respondents were analyzed with SPSS 22.0. Data analysis for hypotheses testing was performed with Anderson and Gerbing (1988)'s two-step approach (evaluating measurement models and structural models). Confirmatory factor analysis (CFA) was first performed to test the measurement model's suitability and evaluate the reliability, convergence validity, and discriminant validity. Then, structural equation modeling (SEM) was performed to test the hypothetical relationship between the seven constructs proposed in the conceptual model.

\section{Results}

\subsection{Measurement model}

CFA evaluates the measurement model fit. Seven common model fit measures such as $\chi^{2} / d f(<3)$, goodness-of-fit index (GFI $\left.>0.9\right)$, root mean square error of approximation (RMSEA $<0.08)$, root mean square residual $(\mathrm{RMR}<0.08)$, normed fit index $(\mathrm{NFI}>0.9$ ), incremental fit index (IFI $>0.9)$, comparative fit index $(\mathrm{CFI}>0.9)$ were used to estimate the measurement model fit (Hair et al. 2016). Table 2 shows CFA results after removing one item of service excellence and one item of novelty that reduce model fit based on the squared multiple correlations (SMC) value. The measurement model had a good fit with the data collected $\left(\chi^{2}=421.055, d f=272\right.$, $p<0.000, \quad \chi^{2} / d f=1.548, \quad \mathrm{RMR}=0.031, \mathrm{GFI}=0.903, \mathrm{NFI}=0.900, \quad \mathrm{IFI}=0.962$, $\mathrm{CFI}=0.962$, RMSEA $=0.043$ ) (See Table 2). The measurement model's adequacy was evaluated based on reliability, convergent validity, and discriminant validity. Reliability was assessed based on the composite construct reliability (CCR) value. Table 2 shows an appropriate CCR with all values exceeding 0.7 (Hair et al. 2016). For all variables, the average variance extracted (AVE) value was higher than the proposed threshold of 0.5, suggesting the scale's convergent validity (Hair et al. 2016).

To examine the discriminant validity of those variables with verified convergent validity, we compared the square root of AVE of each latent variable against the corresponding correlation coefficients between latent variables. Table 3 shows that the square root of AVE of each latent variable is greater than its corresponding 


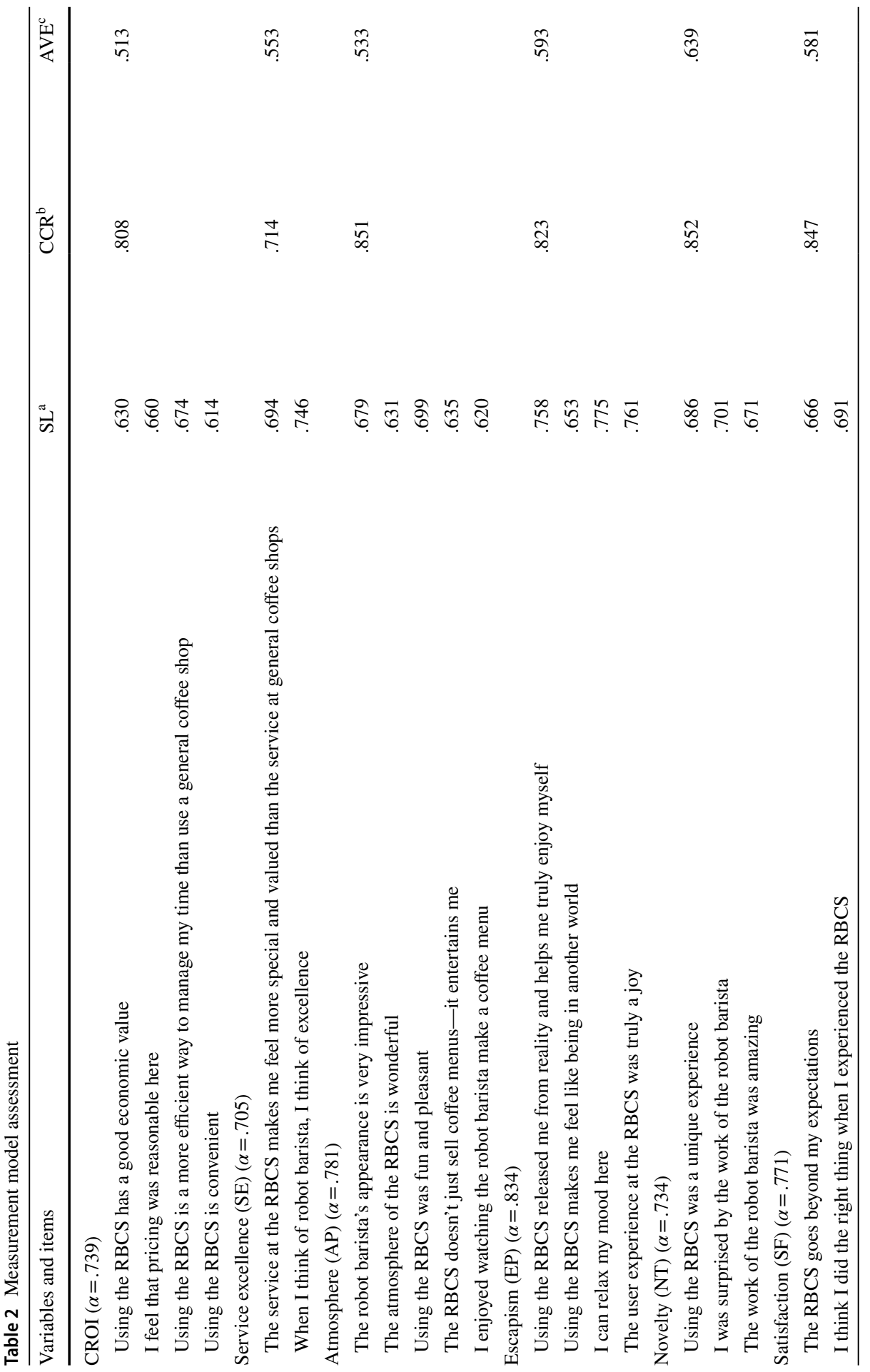




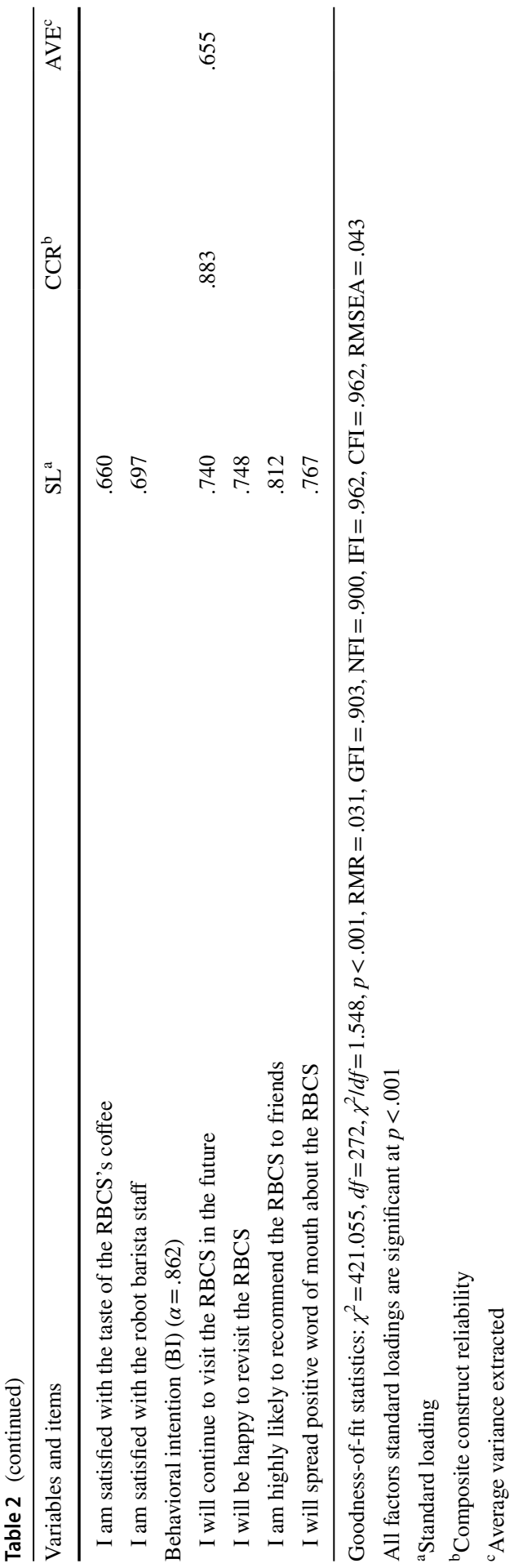


Table 3 Correlations of analysis between the variables

\begin{tabular}{lrrrrrrr}
\hline Variable & \multicolumn{1}{l}{1} & \multicolumn{1}{l}{3} & \multicolumn{1}{l}{4} & \multicolumn{1}{l}{5} & \multicolumn{1}{l}{6} \\
\hline 1. CROI & .716 & & & & & & \\
2. SE & .641 & .744 & & & & & \\
3. AP & .587 & .641 & .730 & & & & \\
4. EP & .650 & .733 & .651 & .770 & & & \\
5. NT & .683 & .730 & .681 & .664 & .799 & & \\
6. SF & .454 & .381 & .714 & .451 & .546 & .762 & \\
7. BI & .639 & .697 & .679 & .688 & .779 & .482 & .809 \\
Mean & 3.840 & 3.645 & 3.972 & 3.598 & 3.880 & 4.232 & 3.771 \\
S.D. & .617 & .807 & .589 & .744 & .604 & .576 & .733 \\
\hline
\end{tabular}

Diagonal elements show the square root of AVE. Below the diagonal is the corresponding correlation coefficient

All correlation coefficients were significant at the .001 level

$S D$ standard deviation

correlation coefficient, indicating adequate discriminant validity (Fornell and Larcker 1981).

\subsection{Common method bias}

Since all the variables in this study were collected from each respondent by selfreported response, the relationship between the variables may be distorted owing to common method bias (CMB) (Podsakoff et al. 2003). Therefore, Harman's singlefactor test was performed to minimize the distortion of the relationship between variables due to CMB. In Harman's single-factor test, we conducted a principal component analysis with the unrotated solution.

Traditionally, Harman's single-factor test indicates a problematic common method variance if an exploratory factor analysis (EFA) with all study variables produces eigenvalues. This suggests that the first factor accounts for more than $50 \%$ of the variance among variables (Podsakoff and Organ 1986; Fuller et al. 2016). EFA was conducted by injecting the 26 remaining measurement items of experiential value, novelty, satisfaction, and behavioral intention. The analysis results indicated that the variance explained by the first factor was $43.5 \%$, meeting the reference point of less than $50 \%$. These results imply that the possibility of CMB distorting the results of this study is low (Podsakoff et al. 2003).

\subsection{Structural model}

SEM was conducted using the AMOS 22.0 statistical package. The structural model's fit describing the relationships among constructs was assessed to test the hypotheses established through the SEM path coefficients. The model fit indices were $\chi^{2}=426.425, d f=276, p<0.000, \chi^{2} / d f=1.545, \mathrm{RMR}=0.031, \mathrm{GFI}=0.901$, $\mathrm{NFI}=0.899, \quad \mathrm{IFI}=0.962, \mathrm{CFI}=0.961, \mathrm{RMSEA}=0.043$ meeting the standard 
assessment criteria. The result of each hypothesis test describing the causal relationship between any pair of constructs is presented in Fig. 2. H1 was supported because CROI positively and significantly influences satisfaction $(\beta=0.363, t=2.208$, $p=0.027)$. H2 was rejected because service excellence does not significantly influence satisfaction $(\beta=0.140, t=0.384, p=0.701)$. H3 was supported because atmosphere positively and significantly influences satisfaction $(\beta=1.104, t=3.182$, $p=0.001)$. H4 was rejected because escapism does not significantly influence satisfaction $(\beta=-0.071, t=-0.188, p=0.851)$. H5 was supported because novelty positively and significantly influences satisfaction $(\beta=0.615, t=2.439, p=0.015)$. Lastly, H6 was supported because satisfaction positively and significantly affects behavioral intention $(\beta=0.952, t=11.102, p=0.001)$.

\section{Discussion}

The result of data analysis, it was confirmed that the satisfaction of the robot barista in the coffee shop was affected by the atmosphere, novelty, and CROI. In particular, it was confirmed that atmosphere has the greatest influence on satisfaction. It suggests that experiential value and novelty are an important factor influencing satisfaction in the food tech field. The facility equipment applied with advanced technology and a sophisticated robot barista's appearance and the overall atmosphere of RBCS greatly increase customer satisfaction. Additionally, the convenience and promptness of menu ordering and service effectively manage time, and the

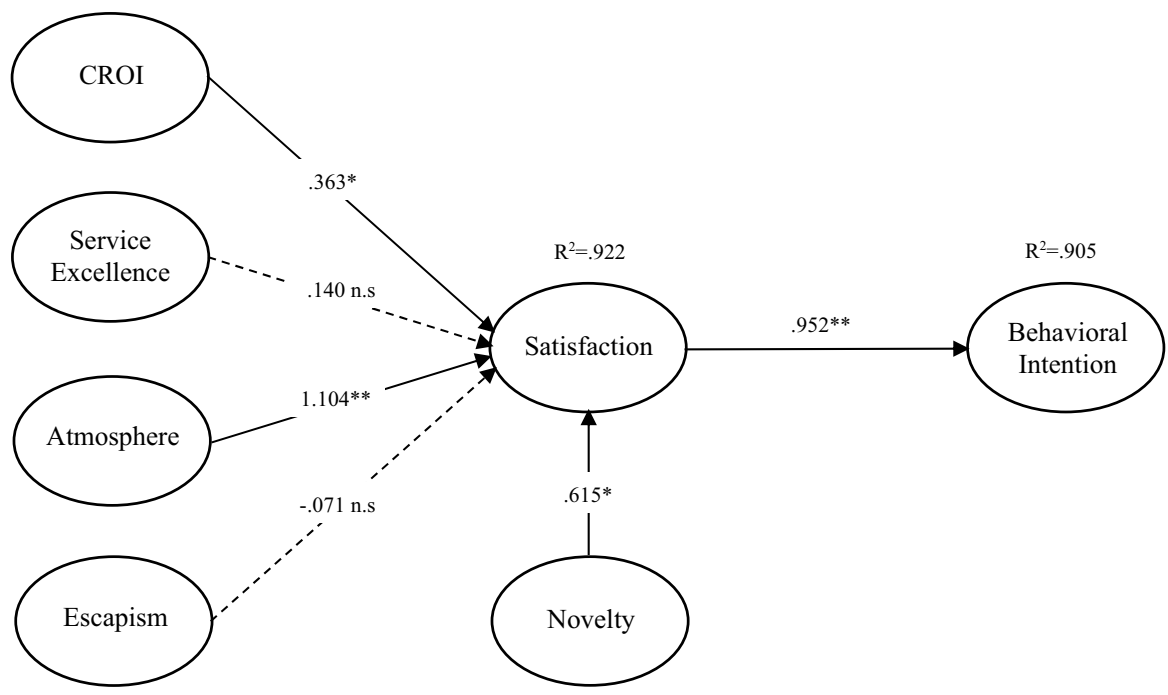

Notes $1: * \mathrm{p}<.05,{ }^{* *} \mathrm{p}<.01 ;$ n.s. $=$ non-significant

Notes 2: Goodness-of-fit statistics for the structural model: $\chi^{2}=426.425, \mathrm{df}=276, \mathrm{p}<.000$, $\chi^{2} / \mathrm{df}=1.545, \mathrm{RMR}=.031, \mathrm{GFI}=.901, \mathrm{NFI}=.899, \mathrm{IFI}=.962, \mathrm{CFI}=.961, \mathrm{RMSEA}=.043$

Fig. 2 Structural equation model with parameter estimates 
reasonable price affects economic value; thus, user satisfaction is evaluated more positively. This result is consistent with a previous study (Chiang 2018; Jin et al. 2013) related to experiential value. However, service excellence was found to have no significant effect on satisfaction. This result contrasts with previous hospitality studies (Hung et al. 2019; Jin et al. 2013; Taylor et al. 2018) related to experiential value. This result is interpreted as a low expected value for contact service because employees do not directly provide services. Also, it was found that escapism did not significantly affect satisfaction. This result contrasts with previous hospitality studies (Hung et al. 2019; Jin et al. 2013; Taylor et al. 2018). These results show that the robot service is limited to the surprise and enjoyment of new experiences and does not satisfy the emotional and psychological impressions of customers. The emotional and psychological impressions of the customer are not satisfied. The novelty was found to increase customer satisfaction for the RBCS. Customers are very surprised and amazed by the robot barista's operation of making and serving orders from the menu, which means that their satisfaction with RBCS increases. This result is consistent with a previous hospitality study (Albaity and Melhem 2017; Chua et al. 2015; Pham and Huang 2015; Toyama and Yamada 2012) related to novelty and satisfaction.

It was confirmed that the satisfaction of using the RBCS increases the behavioral intention. It can be interpreted that experienced users are likely to revisit and recommend if they perceive satisfaction with the robot barista service. This result is consistent with previous hospitality studies' arguments (Ryu et al. 2011; Qin and Prybutox 2008; Taylor et al. 2018) that satisfaction is a positive predictor of behavioral intention.

\section{Conclusions}

This study examines the structural relationship between the variables by applying experiential value and novelty as the preceding consumer behavior variables for robot baristas providing new food tech trends and confirmed the model's suitability. These research designs and results contribute to the literature on robot services. Therefore, the theoretical framework proposed and verified in the model of this study will be the basis for untact service and customer experience research in the post-COVID-19 era in the food and beverage business. Additionally, it is considered a useful study for sustainable coffee shop management when social discussions are needed due to the accelerating digital transformation because of the COVID-19.

\subsection{Theoretical implications}

This study identifies the primary variables that affect customer satisfaction for robot services that will lead the future industry. We researched a RBCS among coffee shops in the food and beverage business. This study's results academic contribute by integrating the food and beverage business's research flow and the latest information technology. 
Experiential value is used in many studies as a cognitive evaluation of the value that customers directly experience in the service situation. Still, there is a limitation in that it cannot predict satisfaction with new service experience in an environment where AI innovation technology is introduced. To overcome this limitation, novelty was added in this study to the experiential value to verify the value perceived after the experience of the menu produced by the robot, unlike previous studies (Lee and Min 2016; Taylor et al. 2018). This design is different from previous experiential value studies (Chiang 2018; Taylor et al. 2018; Tsai and Wang 2017; Wu 2017) on human services in the hospitality industry. This study identifies the relationship between consumers' experiential value and satisfaction regarding non-face-to-face robot service in the foodservice industry. It was identified that the role of atmosphere, novelty, and CROI are important to form customer satisfaction toward RBCS. Additionally, it was confirmed that high customer satisfaction is an important antecedent for behavioral intention. Consequently, this study contributed to the hospitality literature by applying the experience value theory, which had been mainly applied to research on human services, to non-face-to-face service research and identifying its role.

\subsection{Practical implications}

From a practical perspective, to increase customer satisfaction and behavioral intentions for the RBCS, attention should be paid to experiential value and novelty. Coffee consumers in South Korea are more interested in the design and visuals of robot baristas than coffee shops with barista staff and feel amazed and marvel at the innovative technology produced by robot baristas. Therefore, it is necessary to increase further customer's novelty and enjoyment with the delicate visual design and sophisticated performance of the robot barista. Additionally, it is necessary to analyze the human barista's coffee product manufacturing behavior with big data and apply it to AI to be equipped with more advanced service capabilities than the current one. If we manufacture more complex and diverse menus and customize menus according to the customer's current psychological state, emotional and psychological rapport with customers will be formed, increasing the novelty and enjoyment of the robot barista experience.

Whereas customers are accustomed to how they order coffee while communicating with employees; thus, the expectation for the quality of service provided by robot baristas seems low. Robot baristas are an important means of providing services to the spread of untact consumption culture. Therefore, robot baristas should strengthen their AI technology to increase customers' satisfaction in contact services. Now is the time to develop a robot barista that can provide customized service, not an industrial robot. Therefore, to satisfy the consumption needs of the new normal era, aiming for new experiences and untact services, it is necessary to have a robot barista with more enhanced emotions and technology to satisfy the customer. 


\subsection{Limitations and future research}

Despite the results and implications of this study, the following limitations and future research directions are presented. First, the survey was limited to coffee shops in the food and beverage industry. Therefore, it is not appropriate to apply the research results to delivery robots or serving robot services capable of autonomous driving of foodservice. Second, since online surveys can induce selection bias (Wright 2005), various data collection methods should reduce bias and increase response rates in future studies. In the future, if we compare and analyze the experiential value of the RBCS and the human service coffee shop, we will be able to analyze the needs of coffee consumers more clearly.

Acknowledgements No external funding was received for this work.

Author contributions HMJ conceived and designed the experiments; HMJ performed the experiments and analyzed the data; SRY and SHK wrote the paper. All of authors contributed to read and approved the final manuscript.

\section{Declarations}

Conflict of interest The authors declare that they have no conflict of interest.

\section{References}

Adekunle SA, Ejechi JO (2018) Modelling repurchase intention among smartphones users in Nigeria. J Model Manage 13(4):794-814

Alalwan AA (2020) Mobile food ordering apps: an empirical study of the factors affecting customer e-satisfaction and continued intention to reuse. Int J Inf Manage 50(February):28-44

Albaity M, Melhem SB (2017) Novelty seeking, image, and loyalty-the mediating role of satisfaction and moderating role of length of stay: international tourists' perspective. Tour Manage Persp 23(July):30-37

Ali S, Khalid N, Javed HMU, Islam DM (2021) Consumer adoption of online food delivery ordering (OFDO) services in Pakistan: the impact of the COVID-19 pandemic situation. J Open Innov: Technol Mark Complex 7(1):10

Anderson JC, Gerbing DW (1988) Structural equation modeling in practice: a review and recommended two-step approach. Psychol Bull 103(3):411-423

Anderson EW, Mittal V (2000) Strengthening the satisfaction-profit chain. J Serv Res 3(2):107-120

Belanche D, Casaló LV, Flavián C, Schepers J (2020) Robots or frontline employees? Exploring customers' attributions of responsibility and stability after service failure or success. J Serv Manage 31(2):267-289

Berry LL, Carbone LP, Haeckel SH (2002) Managing the total customer experience. MIT Sloan Manage Rev 43(3):85-89

Bolton RN, Lemon KN (1999) A dynamic model of customers' usage of services: usage as an antecedent and consequence of satisfaction. J Mark Res 36(2):171-186

Boulding W, Kalra A, Staelin R, Zeithaml VA (1993) A dynamic process model of service quality: from expectations to behavioral intentions. J Mark Res 30(1):7-27

Chiang CH (2018) Experiential value affects purchase intentions for online-to-offline goods: consumer feedback as a mediator. J Mark Manage 6(2):10-24

Chua BL, Lee S, Goh B, Han H (2015) Impact of cruise service quality and price on vacationers' cruise experience: moderating role of price sensitivity. Int J Hosp Manage 44(January):131-145 
Dedeoglu BB, Bilgihan A, Ye BH, Buonincontri P, Okumus F (2018) The impact of servicescape on hedonic value and behavioral intentions: the importance of previous experience. Int J Hosp Manage 72(June): 10-20

Fornell C (1992) A national customer satisfaction barometer: the Swedish experience. J Mark 56(1):6-21

Fornell C, Larcker DF (1981) Evaluating structural equation models with unobservable variables and measurement error. J Mark Res 18(1):39-50

Fuller CM, Simmering MJ, Atinc G, Atinc Y, Babin BJ (2016) Common methods variance detection in business research. J Bus Res 69(8):3192-3198

Gallarza MG, Saura IG (2006) Value dimensions, perceived value, satisfaction and loyalty: an investigation of university students' travel behavior. Tour Manage 27(3):437-452

Hair JF, Hult GTM, Ringle C, Sarstedt M (2016) Primer on partial least squares structural equation modelling (PLS-SEM). Sage, Los Angles, CA, USA

Harkness J (2011) Guidelines for best practice in cross-cultural surveys. University of Michigan Institute for Social Research, Ann Arbor

Hirschman EC (1980) Innovativeness, novelty seeking and consumer creativity. J Consum Res 7(3):283-295

Holbrook MB (1994) The nature of customer value: an axiology of services in the consumption experience. In: Rust RT, Oliver RL (eds) Service quality: new directions in theory and practice. Sage, Thousand Oaks, CA, pp 21-71

Hung KP, Peng N, Chen A (2019) Incorporating on-site activity involvement and sense of belonging into the Mehrabian-Russell model-the experiential value of cultural tourism destinations. Tour Manage Persp 30(April):43-52

Infostock Daily (2020) Dalkom coffee robot café 'Bit 2E' first opened in 'E-Mart Cheonggyecheon'. http://www.infostockdaily.co.kr/news/articleView.html?idxno=84850. Accessed 15 July 2021

Jang HW, Lee SB (2020) Serving robots: management and applications for restaurant business sustainability. Sustainability 12(10):3998

Jheng YC, Chou YB, Kao CL, Yarmishyn AA, Hsu CC, Lin TC, Hwang DK (2020) A novelty route for smartphone-based artificial intelligence approach to ophthalmic screening. J Chin Med Assoc 83(10):898-899

Jin N, Line ND, Goh B (2013) Experiential value, relationship quality, and customer loyalty in fullservice restaurants: the moderating role of gender. J Hosp Mark Manage 22(7):679-700

Karjaluoto H, Shaikh AA, Saarijärvi H, Saraniemi S (2019) How perceived value drives the use of mobile financial services apps. Int J Inf Manage 47(August):252-261

Keng CJ, Huang TL, Zheng LJ, Hsu M (2007) Modeling service encounters and customer experiential value in retailing. Int J Serv Indus Manage 18(4):349-367

Kim JH (2010) Determining the factors affecting the memorable nature of travel experiences. J Travel Tour Mark 27(8):780-796

Kim MS, Stepchenkova S (2018) Examining the impact of experiential value on emotions, self-connective attachment, and brand loyalty in Korean family restaurants. J Qual Assur Hosp Tour 19(3):298-321

Kim JH, Ritchie JRB, McCormick B (2012) Development of a scale to measure memorable tourism experiences. J Travel Res 51(1):12-25

Lee TH, Crompton J (1992) Measuring novelty seeking in tourism. Annal Tour Res 19(4):732-751

Lee SM, Lee D (2020) "Untact": a new customer service strategy in the digital age. Serv Bus 14(1):1-22

Lee JS, Min CK (2016) Examining the quality antecedents and moderating effects of experiential value in a mega-event. J Travel Tour Mark 33(3):326-347

Lee S, Chua BL, Han H (2017) Role of service encounter and physical environment performances, novelty, satisfaction, and affective commitment in generating cruise passenger loyalty. Asia Pacific J Tour Res 22(2):131-146

Lin H, Chi OH, Gursoy D (2020) Antecedents of customers' acceptance of artificially intelligent robotic device use in hospitality services. J Hosp Mark Manage 29(5):530-549

Maghnati F, Ling KC (2013) Exploring the relationship between experiential value and usage attitude towards mobile apps among the smartphone users. Int J Bus Manage 8(4):1-9

Manthiou A, Kang J, Hyun SS (2017) An integration of cognitive appraisal theory and script theory in the luxury cruise sector: the bridging role of recollection and storytelling. J Travel Tour Mark 34(8):1071-1088 
Mathwick C, Malhotra NK, Rigdon E (2001) Experiential value: conceptualization, measurement and application in the catalog and Internet shopping environment. J Retail 77(1):39-56

Mathwick C, Malhotra NK, Rigdon E (2002) The effect of dynamic retail experiences on experiential perceptions of value: an Internet and catalog comparison. J Retail 78(1):51-60

Murphy J, Hofacker C, Gretzel U (2017) Dawning of the age of robots in hospitality and tourism: challenges for teaching and research. Eur J Tour Res 15:104-111

Oliver RL (1980) A cognitive model of the antecedents and consequences of satisfaction decisions. J Mark Res 17(4):460-469

Oliver RL (1997) Satisfaction: a behavioral perspective on the consumer. McGraw-Hill, NY

Oliver R, DeSarbo WS (1988) Response determinants in satisfaction judgments. J Consum Res 14(4):495-507

Petrick JF (2002) Development of a multi-dimensional scale for measuring the perceived value of a service. J Leisure Res 34(2):119-134

Pham TH, Huang YY (2015) The impact of experiential marketing on customer's experiential value and satisfaction: an empirical study in Vietnam hotel sector. J Bus Manage Social Sci Res 4(1):1-19

Podsakoff PM, Organ D (1986) Self-reports in organizational research: problems and prospects. J Manage 12(4):531-544

Podsakoff PM, MacKenzie SB, Lee JY, Podsakoff NP (2003) Common method biases in behavioral research: a critical review of the literature and recommended remedies. J Appl Psychol 88(5):879-903

Qin H, Prybutox VR (2008) Determinants of customer-perceived service quality in fast-food restaurants and their relationship to customer satisfaction and behavior intentions. Qual Manage J 15(2):35-41

Ratner RK, Kahn BE, Kahneman D (1999) Choosing less-preferred experiences for the sake of variety. J Consum Res 26(1):1-15

Rezaei S, Valaei N (2017) Crafting experiential value via smartphone apps channel. Mark Intell Plan 35(5):688-702

Robot newspaper (2020) Roboworld. http://www.irobotnews.com/news/articleView.html?idxno=22735. Accessed 15 July 2021

Ryu K, Han H (2011) New or repeat customers: how does physical environment influence their restaurant experience? Int J Hosp Manage 30(3):599-611

Ryu K, Han H, Jang S (2010) Relationships among hedonic and utilitarian values, satisfaction and behavioral intentions in the fast-casual restaurant industry. Int J Contemp Hosp Manage 22(3):416-432

Sharma JK, Kumar N (2019) Service quality, satisfaction and behavioural intention: mediation and interaction analysis in electronic food ordering services. Acad Mark Stud J 23(3):1-15

Sheth JN, Newman BI, Gross BL (1991) Why we buy what we buy: a theory of consumption values. J Bus Res 22(2):159-170

Song HJ, Wang JH, Han H (2019) Effect of image, satisfaction, trust, love, and respect on loyalty formation for name-brand coffee shops. Int J Hosp Manage 79(May):50-59

Sung HJ, Jeon HM (2020) Untact: customer's acceptance intention toward robot barista in coffee shop. Sustainability 12(20):8598

Szymanski DM, Henard DH (2001) Customer satisfaction: a meta-analysis of the empirical evidence. J Acad Mark Sci 29(1):16-35

Taylor SA, Baker TL (1994) An assessment of the relationship between service quality and customer satisfaction in the formation of consumers' purchase intentions. J Retail 70(2):163-178

Taylor S Jr, DiPietro RB, So KKF (2018) Increasing experiential value and relationship quality: an investigation of pop-up dining experiences. Int J Hosp Manage 74(August):45-56

Toyama M, Yamada Y (2012) The relationships among tourist novelty, familiarity, satisfaction, and destination loyalty: beyond the novelty-familiarity continuum. Int J Mark Stud 4(6):10-18

Tsai CT, Wang YC (2017) Experiential value in branding food tourism. J Destin Mark Manage 6(1):56-65

Tuomi A, Tussyadiah IP, Stienmetz J (2021) Applications and implications of service robots in hospitality. Cornell Hosp Q 62(2):232-247

Vilnai-Yavetz I, Rafaeli A (2006) Aesthetics and professionalism of virtual servicescapes. J Serv Res $8(3): 245-259$

World Health Organization (2020) WHO Director-General's opening remarks at the media briefing on COVID-19-11 March 2020. https://www.who.int/director-general/speeches/detail/who-directorgeneral-s-opening-remarks-at-the-media-briefing-on-covid-19---11-march-2020. Accessed 26 Jan 2021. 
Wright KB (2005) Researching internet-based populations: advantages and disadvantages of online survey research, online questionnaire authoring software packages, and web survey services. J Comp Mediate Commun. https://doi.org/10.1111/j.1083-6101.2005.tb00259.x

Wu HC (2017) What drives experiential loyalty? A case study of Starbucks coffee chain in Taiwan. British Food J 119(3):468-496

Wu CHJ, Liang RD (2009) Effect of experiential value on customer satisfaction with service encounters in luxury-hotel restaurants. Int J Hosp Manage 28(4):586-593

Yuan YHE, Wu CK (2008) Relationships among experiential marketing, experiential value, and customer satisfaction. J Hosp Tour Res 32(3):387-410

Zeithaml VA, Berry LL, Parasuraman A (1996) The behavioral consequences of service quality. J Mark 60(2):31-46

Zeng Z, Chen PJ, Lew AA (2020) From high-touch to high-tech: COVID-19 drives robotics adoption. Tour Geogr 22(3):724-734

Publisher's Note Springer Nature remains neutral with regard to jurisdictional claims in published maps and institutional affiliations. 